\title{
Arsenic-stimulated liver sinusoidal capillarization in mice requires NADPH oxidase-generated superoxide
}

\author{
Adam C. Straub,, ${ }^{1}$ Katherine A. Clark, ${ }^{2}$ Mark A. Ross, ${ }^{2}$ Ashwin G. Chandra, ${ }^{1}$ Song Li, ${ }^{3}$ \\ Xiang Gao,, ${ }^{3}$ Patrick J. Pagano, ${ }^{4}$ Donna B. Stolz, ${ }^{2,5}$ and Aaron Barchowsky ${ }^{1,5}$ \\ ${ }^{1}$ Department of Environmental and Occupational Health, ${ }^{2}$ Department of Cell Biology and Physiology, ${ }^{3}$ Department of Pharmaceutical Science, ${ }^{4}$ Department of \\ Pharmacology and Chemical Biology, and ${ }^{5}$ Center for Vascular Remodeling and Regeneration, University of Pittsburgh, Pittsburgh, Pennsylvania, USA.
}

\begin{abstract}
Environmental arsenic exposure, through drinking contaminated water, is a significant risk factor for developing vascular diseases and is associated with liver portal hypertension, vascular shunting, and portal fibrosis through unknown mechanisms. We found that the addition of low doses of arsenite to the drinking water of mice resulted in marked pathologic remodeling in liver sinusoidal endothelial cells (SECs), including SEC defenestration, capillarization, increased junctional PECAM-1 expression, protein nitration, and decreased liver clearance of modified albumin. Furthermore, the pathologic changes observed after in vivo exposure were recapitulated in isolated mouse SECs exposed to arsenic in culture. To investigate the role of NADPH oxidase-generated ROS in this remodeling, we examined the effect of arsenite in the drinking water of mice deficient for the p47 subunit of the NADPH oxidase and found that knockout mice were protected from arsenite-induced capillarization and protein nitration. Furthermore, ex vivo arsenic exposure increased SEC superoxide generation, and this effect was inhibited by addition of a Nox 2 inhibitor and quenched by the cellpermeant superoxide scavenger. In addition, inhibiting either oxidant generation or Rac1-GTPase blocked ex vivo arsenic-stimulated SEC differentiation and dysfunction. Our data indicate that a Nox2-based oxidase is required for SEC capillarization and that it may play a central role in vessel remodeling following environmentally relevant arsenic exposures.
\end{abstract}

\section{Introduction}

Arsenic is a toxic metalloid that constitutes $0.0001 \%$ of the Earth's crust and is a common contaminant of drinking water. Drinking arsenic-contaminated water increases risk of cardiovascular disease, lung disease, hepatic disease, and cancer in millions of people worldwide. The World Health Organization and the United States Environmental Protection Agency have set the drinking water standard for arsenic at 10 parts per billion (ppb) based on cancer risk. However, even at this low level, arsenic may increase the occurrence of cardiovascular disease in humans (1-3) and promotes angiogenesis and vascular remodeling in mice (4, 5). Epidemiological studies demonstrate that arsenic increases risk for many vascular pathologies, including peripheral vascular disease, ischemic heart disease, acute myocardial infarction, atherosclerosis, and hypertension (2, 6-8). In addition, vascular remodeling and shunting is commonly observed in arsenic-related liver diseases, such as portal hypertension and noncirrhotic liver fibrosis (9). The pathological mechanisms that contribute to angiogenesis and vascular remodeling in response to arsenic exposures remain unresolved.

Liver sinusoidal endothelial cells (SECs) are unique endothelial cells in both their architecture and their function. The sinusoids are the exchange vessels of the liver, and the SECs are distinguished by extensive fenestrations organized into sieve plates, a lack of a basement membrane, and low junctional expression of

Nonstandard abbreviations used: $\mathrm{ppb}$, part(s) per billion; SEC, sinusoidal endothelial cell; tempol, 4-hydroxy-2,2,6,6-tetramethylpiperidine 1-oxyl.

Conflict of interest: The authors have declared that no conflict of interest exists. Citation for this article: J. Clin. Invest. doi:10.1172/JCI35092.
PECAM-1 (also known as CD31). The SEC architecture, including open fenestrations and weak junctional association between cells, provides a dynamic filtration system with low perfusion pressure that enables nutrients and macromolecular waste to pass freely to hepatocytes for efficient metabolism. The highly active, clathrinmediated scavenging system in the SEC contributes significantly to endocytic clearance of waste from blood, including effective removal of pathogenic acylated or glycosylated proteins $(10,11)$. In addition, the SECs are antigen-presenting cells, and interactions with SECs and underlying hepatocyte microvilli may be important for naive $\mathrm{T}$ cell activation (12). Loss of these important SEC functions as a result of age or environmental stresses has been proposed to contribute to risk for systemic vascular diseases as well as hepatic pathogenesis $(11,13,14)$.

The maintenance of the SEC phenotype is a critical, but poorly understood, process that requires both autocrine and paracrine cell signaling. Results of recent studies indicate that SEC fenestrations are maintained by constitutive VEGF-stimulated NO generation in the SECs and surrounding cells (15). SEC NO generation, in turn, promotes quiescence of surrounding stellate cells that are profibrotic when activated (16). In response to ethanol (17), oxidizing chemicals (18), surfactants (19), and aging (13), SECs dedifferentiate into a more regular endothelium in a process termed capillarization or pseudocapillarization. The hallmarks of capillarization are SEC defenestration, development of a lamininrich basement membrane, and junctional expression of PECAM. Sinusoidal stellate cells are also induced to overexpress a laminin and collagen matrix that contributes to fibrosis (16). Capillarization precedes the development of many liver diseases, including both portal hypertension and liver fibrosis. In addition, loss of 
A

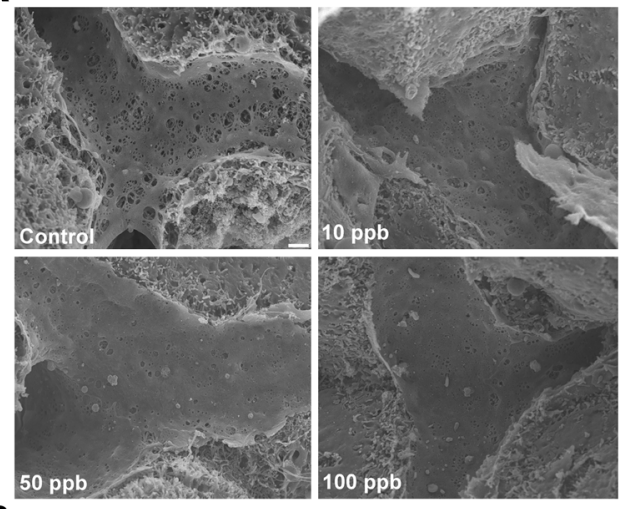

B

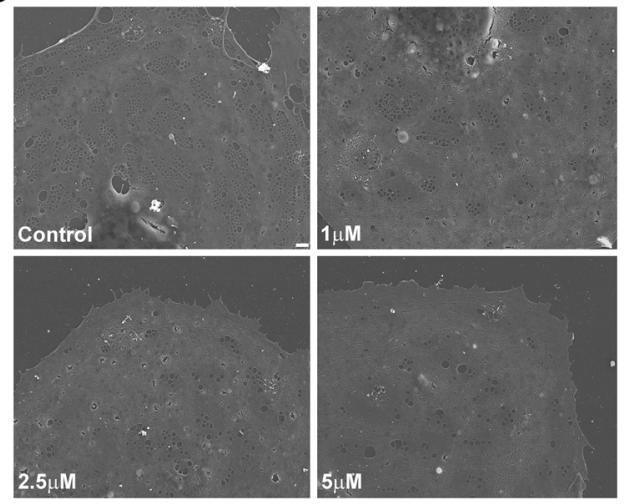

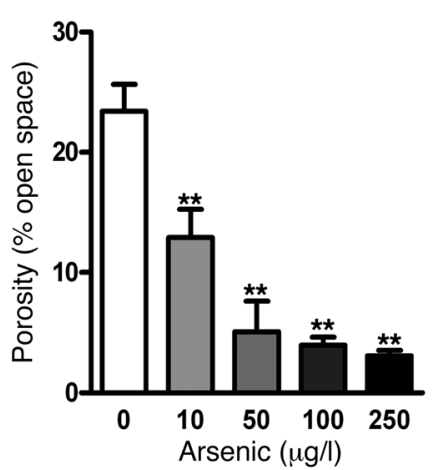

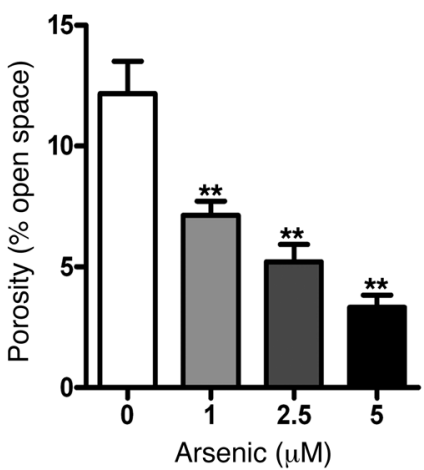

Figure 1

Arsenite-stimulated defenestration and capillarization in vivo and ex vivo. (A) Representative scanning EM images were captured from liver sections of control mice or mice exposed for $2 \mathrm{wk}$ to $10-250 \mathrm{ppb}$ arsenite in their drinking water. Morphometric analysis was used to calculate porosity (percent of open space in the fenestrations relative to area of vessel wall) from 10 midlobular sinusoid vessel images from each of 3 separate mice per treatment group. Data are mean $\pm S D$, with significance of differences determined by ANOVA followed by Dunnet's post test ( $n=3$ mice per treatment). (B) Primary cultured SECs were exposed ex vivo to arsenite at the indicated concentrations for $8 \mathrm{~h}$. Cells were fixed and processed for scanning EM imaging at $\times 10,000$ magnification. Data are mean \pm SD from analysis of 5 images from 5 individual coverslips of cells per treatment ( $n=4$ mice per treatment). ${ }^{* *} P<0.01$ versus control. Scale bars: $1 \mu \mathrm{m}$. lipid metabolism or removal of acylated or glycolated proteins following capillarization may enhance atherosclerosis, insulin resistance, and possibly metabolic disease (13, 20, 21). Recently, environmental arsenic exposures (250 ppb) were shown to promote progressive SEC capillarization in intact mice through an unresolved mechanism $(22,23)$.

Superoxide and subsequent ROS generation by Nox-containing NADPH oxidase enzyme complexes in endothelial and smooth muscle cells are fundamental to neovascularization, angiogenesis, and vessel remodeling caused by a variety of endogenous and exogenous factors $(24,25)$. Arsenic stimulates Nox-based oxidase activity in cultured large vessel vascular cells $(26,27)$ through mobilization and activation of Rac1-GTPase (26) and increases Rac1 association with SEC membranes during capillarization (22). However, there are no reports of the functional role of this mobilization in capillarization, nor are there reports of a functional role for Rac1-stimulated SEC NADPH oxidase in capillarization in general. In the present study, we investigated the hypothesis that arsenic stimulates SEC Rac1 and oxidase activity to close fenestrations, promote capillarization, and disrupt the physiological function of scavenging modified proteins. The results from the in vivo experiments are the first to our knowledge to demonstrate that low-level arsenic exposure stimulates dose-dependent SEC capillarization through activation of p47phox-containing NADPH oxidase enzyme complexes. Ex vivo studies in primary SECs indicated that capillarization was a direct effect of arsenic on the SECs that required Rac1. In addition to identifying a mechanism for the vascular effects of arsenic, our results revealed an essential role for Nox2-based oxidase in the pathogenesis of capillarization.

\section{Results}

Arsenic stimulated dose-dependent capillarization and PECAM-1 expression in vivo and ex vivo. Previous studies demonstrated that $250 \mathrm{ppb}$ arsenite in drinking water resulted in progressive SEC defenestration and capillarization that was maximal within $2 \mathrm{wk}$ (23). The threshold for these pathologic changes was below the current maximal containment level of $10 \mathrm{ppb}$, and loss of porosity was dose dependent between 10 and $100 \mathrm{ppb}$ (Figure 1A). The open dilated fenestrations and numerous sieve plates in control mice were lost, and the arsenite-exposed SECs formed tighter junctions. The loss in porosity was caused by a decrease in both number and size of fenestrations, and, as we have previously reported (22), there was no difference in the degree of arsenic effects between zones 1 and 3 of the sinusoidal beds. Capillarization was confirmed in confocal images of sections stained with anti-PECAM-1, demonstrating a reciprocal dose-response relationship for arsenic-stimulated junctional PECAM-1 expression relative to porosity (Figure 2A). As in previous studies $(22,23)$, there were no signs of SEC injury or cell death, nor were there any signs of injury in surrounding stellate cells or hepatocytes.

Ex vivo exposure of primary cultured SECs to 1-5 $\mu \mathrm{M}$ arsenite for $8 \mathrm{~h}$ recapitulated the in vivo observations, with arsenic causing defenestration and disorganized, consolidated sieve plates (Figure 1B). As seen in vivo, arsenite caused a concentration-dependent increase in junctional PECAM-1 expression as the sieve plates were lost (Figure 2B). These results demonstrate that direct SEC effects may account for arsenite-stimulated capillarization.

Arsenic decreased SEC scavenger receptor function in vivo. A major physiological role of the SECs is scavenging of small macromolecules, such as chylomicron and derivatized plasma proteins (11). 
A
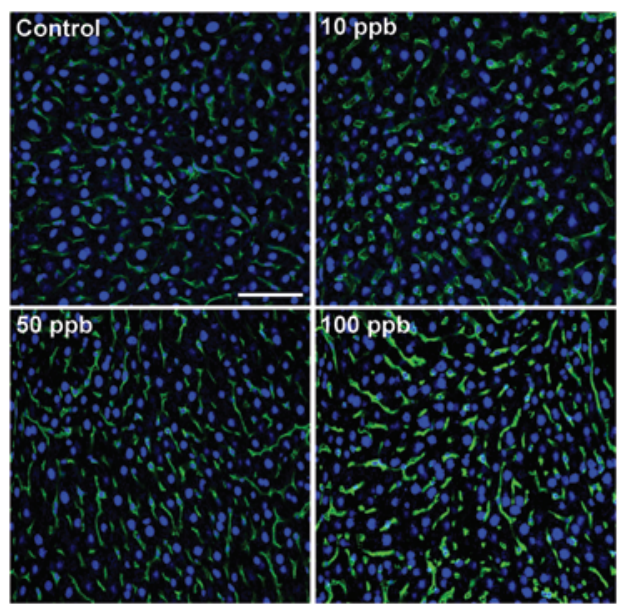

B

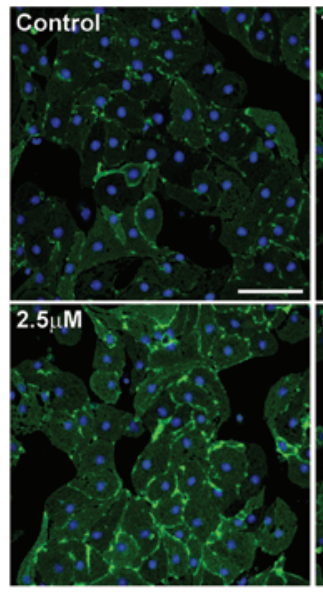

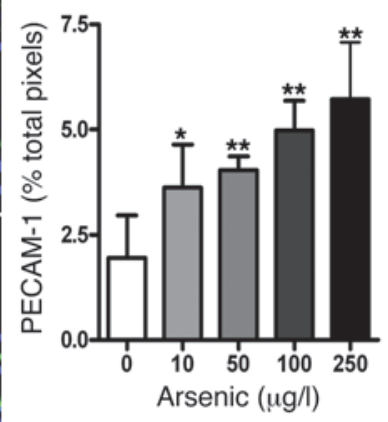

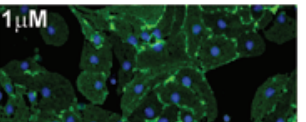

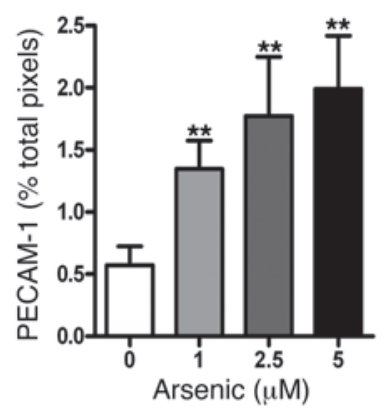

\section{Figure 2}

Arsenite stimulated junctional PECAM-1 expression. (A) Immunofluorescent analysis of PECAM-1 expression (green) and nuclei (blue) was captured from 5 representative midlobular liver sections treated as in Figure 1A. Quantitative morphometric analysis shows mean \pm SD percentage of total green positive-staining pixels for PECAM-1 per $\times 400$ field. Significance of differences was determined using ANOVA followed by Dunnet's post test ( $n=4$ mice per treatment). (B) Isolated SECs were treated as in Figure 1B, fixed, and analyzed by immunofluorescence imaging for PECAM-1 expression (green) and nuclei (blue; DRAQ5). Images were captured at $\times 400$ magnification. Data (mean $\pm \mathrm{SD}$ ) show PECAM-1-positive staining relative to DRAQ5 nuclei in 3 images from 5 individual cultures per treatment generated from 3 separate livers. ${ }^{\star} P<0.05$, ${ }^{* *} P<0.01$ versus control. Scale bars: $10 \mu \mathrm{m}$.
Comparison of liver clearance of biotinylated or FITC-labeled BSA with succinylated BSA was used to examine whether exposure to arsenic functionally impaired SECs. Only the labeled succinylated BSA was taken up in the liver sinusoids relative to labeled native BSA (Figure 3A). Arsenic decreased clearance of biotinylated succinylated BSA by $60 \%$ relative to untreated control mice (Figure $3 \mathrm{~B}$ ). A similar decrease was observed in isolated SECs exposed to arsenic ex vivo (Figure 3C). Thus, arsenic-stimulated capillarization was associated with functional loss of physiological scavenging of modified proteins by the SEC.

p47phox knockout SECs are protected from arsenic-stimulated capillarization. Oxidants and compounds that generate oxidants promote capillarization $(13,18)$. Because arsenic stimulates NADPH oxidase-derived ROS formation in large vessel endothelial cells (26), we tested whether a similar mechanism mediates arsenic effects in SECs. Mice deficient in the canonical Nox2-based oxidase subunit $\mathrm{p} 47^{\mathrm{phox}}$ were exposed for $2 \mathrm{wk}$ to $100 \mathrm{ppb}$ arsenic in their drinking water to test the relevance of this oxidase to capillarization in vivo. Controls for these exposures included wild-type and arsenite-exposed mice that were maintained on the same antibiotic and housed on the same bedding as the immunocompromised $47^{\text {phox }}$ knockouts. We found that sinusoids in the knockout mice did not capilliarize in response to arsenic (Figure 4, A-C). In addition, ex vivo addition of arsenic failed to decrease porosity in SECs isolated from these knockout mice
(Figure 4D). In contrast, addition of $\mathrm{H}_{2} \mathrm{O}_{2}$ bypassed the lack of oxidase activity in these cells and reduced porosity by 4 -fold. The knockout mice were protected from other endpoints of capillarization, such as forming a basement membrane and increased hepatocyte microvilli in response to arsenic (Figure 4C). Finally, arsenic-increased nitration of sinusoidal proteins, an indicator of peroxynitrite formation, was absent in the exposed p47phox knockout mice (Figure 5). These results demonstrate that superoxide and $\mathrm{H}_{2} \mathrm{O}_{2}$ generated by $\mathrm{p}^{4} 7$ phox-containing NADPH oxidase contributed significantly to capillarization.

SEC Nox2 oxidase activity is necessary and sufficient to mediate arsenic-induced capillarization. Primary SECs in culture were exposed to arsenite ex vivo to address whether SEC NADPH oxidase activity was sufficient to mediate the effects of arsenic on SEC function and capillarization. First, SECs loaded with superoxide-sensitive dihydroethidium increased their fluorescence, as measured by hydroethidium formation, within $30 \mathrm{~min}$ of arsenic exposure (Figure 6). This increase followed the same concentration dependence as decreased porosity (Figure 1) and increased junctional PECAM-1 expression (Figure 2). Preincubation of the cells with the superoxide scavenger 4-hydroxy-2,2,6,6-tetramethylpiperidine 1-oxyl (tempol) prevented arsenite-increased hydroethidium fluorescence (Figure 6), prevented loss of scavenging function (Figure 3C), and both decreased porosity and increased junctional PECAM-1 expression (Figure 7). Likewise, preincubation 
A
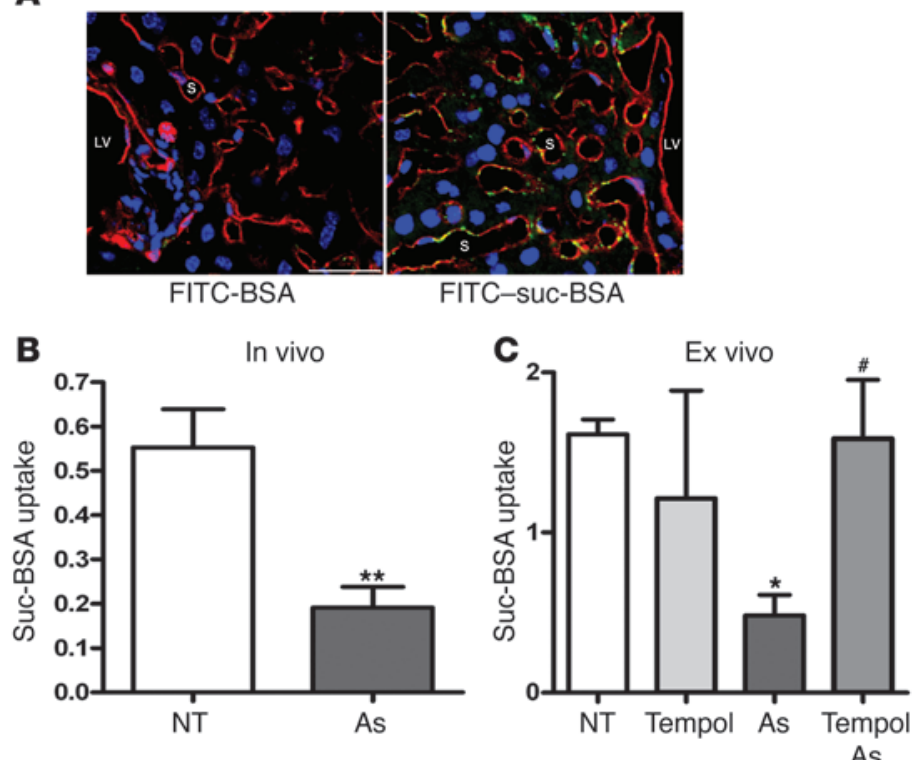

\section{Figure 3}

Arsenic inhibits SEC scavenging of acylated protein. (A) Mice were injected in the tail vein with $150 \mathrm{mg} / \mathrm{kg}$ FITC-labeled succinylated BSA (suc-BSA) or BSA (both green) in $200 \mu$ l saline. After $10 \mathrm{~min}$, the mice were euthanized, and livers were excised, fixed in $4 \%$ paraformaldehyde, and sectioned for confocal microscopic analysis. Sections were stained with rhodamine-conjugated antibody to PECAM-1 (red) and DRAQ5 (blue). Images are representative of sections from 3 mice in each group. LV, large vessel; S, sinusoid vessel. Scale bar: $10 \mu \mathrm{m}$. (B) FITC-labeled acetylated LDL and biotin-labeled succinylated BSA $(3 \mathrm{ml}$; $150 \mathrm{mg} / \mathrm{ml}$ saline) were infused over 3 min into the vena cavas of untreated mice and mice exposed to $100 \mathrm{ppb}$ arsenic (As) for $2 \mathrm{wk}$. Livers were then excised, frozen in liquid $\mathrm{N}_{2}$, and sectioned, and total protein was extracted for assay of retained biotin label by immunoblotting, as described in Methods. Data are mean \pm SD band density of biotin-labeled succinylated BSA normalized to $\beta$-actin $(n=3)$. NT, not treated. (C) Isolated SECs, incubated in the absence or presence of $1 \mathrm{mM}$ tempol for $10 \mathrm{~min}$, were left untreated or exposed to $2.5 \mu \mathrm{M}$ arsenite for $24 \mathrm{~h}$. Biotin-labeled succinylated BSA $(20 \mu \mathrm{g} / \mathrm{ml})$ was then added for $10 \mathrm{~min}$, and after rinsing, total proteins were extracted for Western analysis $(n=3)$. Data are presented as in $\mathbf{B}$. ${ }^{\star} P<0.05,{ }^{* *} P<0.01$ versus control; $\# P<0.05$ versus arsenic. of the cells with gp91ds-tat peptide (an inhibitor designed to disrupt Nox2-based oxidase protein complexes; ref. 28), but not the scrambled-tat control peptide, prevented the arsenite-stimulated superoxide generation and morphologic change (Figures 6 and 7). These results from isolated SECs, combined with the results from the p47phox knockout mice in Figures 4 and 5, suggest that the canonical p47phox containing Nox2-based oxidase, and its attendant superoxide generation, is necessary and sufficient to mediate arsenite-stimulated SEC capillarization and dysfunction.

Rac1-GTPase activity in arsenite-stimulated capillarization. Rac1 is an essential component of the Nox2-based oxidase required for arsenite-stimulated large-vessel NADPH oxidase activity (26). Arsenic mobilized Rac1 to the SEC plasma membrane during capillarization in vivo (22), but the function of this mobilization was unknown. Therefore, the role of Rac1 in arsenicinduced capillarization was tested by examining the effects of a chemical inhibitor of Rac1, NSC23766 (29), on arsenic-stimulated defenestration. Overnight preincubation of the SECs with NSC23766 prevented arsenite-reduced porosity and arseniteincreased junctional PECAM-1 expression (Figure 8), which indicates that Rac1 activity is essential for arsenite-stimulated SEC capillarization. Because NSC23766 inhibits Rac1-GTPase activity but not membrane mobilization (29), these data suggest that the initial step in arsenic-stimulated oxidant signaling in SEC is upstream of Rac1 activation.

\section{Discussion}

Pathological vascular remodeling, such as neovascularization, angiogenesis, and morphologic changes in vascular architecture, in response to environmental insults is a critical processes for the development of many vascular diseases, including atherosclerosis, cardiovascular ischemic diseases, tumor vasculogenesis, and liver fibrosis. The current studies focused on a unique form of vascular remodeling, sinusoidal capillarization, that is known to pathologically compromise the SECs and the effective exchange of nutrients and waste in the liver. Capillarization precedes remodeling and shunting in the progression of liver fibrosis $(30,31)$ and allows induction of profibrotic collagen expression in sinusoidal stellate cells (16). Decreased liver metabolism of lipids, glucose, and other nutrients promotes atherogenesis after capillarization in response to several environmental stressors and aging $(13,18)$. We previously demonstrated that arsenic stimulates SEC capillarization and remodeling of the liver vasculature $(22,23)$. Our present results provide support for an arsenic-stimulated mechanism that requires Nox2-based oxidase-generated oxidants to defenestrate and capilliarize SECs as well as impair their physiological functions. In addition, this study is the first to our knowledge to demonstrate a functional consequence of this oxidase activity in SEC capillarization, a process that has been proposed to be oxidant mediated $(18,21)$. The potential public health implications of these findings are that they suggest that stimulation of Nox2-based oxidase in the SECs, and perhaps other vascular beds, is a fundamental mechanism for the etiology of arsenic-promoted hepatic and systemic vascular diseases.

There have been few reports of a direct physiologic or pathophysiologic role of SEC oxidase enzymes. Several studies demonstrated that oxidants, surfactants, and oxidizing conditions in aging promote capillarization to alter circulating lipid and lipoprotein profiles $(13,18,19)$. However, the mechanisms for SEC oxidant generation other than direct chemical action were not investigated in these studies. In rats, high-level ethanol perfusions stimulate SEC and Kupffer cell superoxide production that is inhibited by the nonselective flavoprotein inhibitor diphenyleneiodonium chloride (17), and chronic coexposure to drinking water ethanol and high levels of injected arsenic (i.e., $100 \mathrm{ppm}$ ) promote oxidant-dependent vascular channeling and fibrosis (32). A proposed mechanism for the observed liver pathology was depletion of antioxidant glutathione (32), which was unlikely to occur during the shorter and lower-level arsenic exposure in the current study.

Dorman et al. proposed that either SEC or neutrophil Nox2 participates in sinusoidal injury secondary to hind-limb ischemia, since gp91ds-tat protected the hepatic parenchymal and endothelial cells from oxidative injury in this in vivo model (33). This model produced significant inflammation, and much of the parenchymal injury was mediated by activated neutrophils (33). In contrast, we 
A

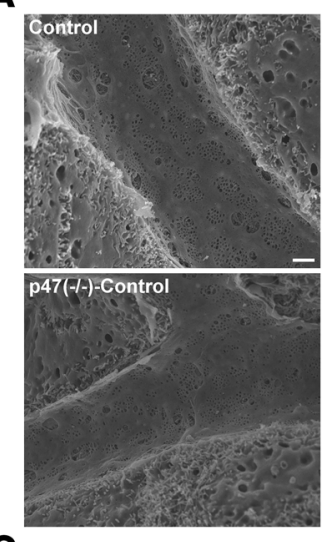

C
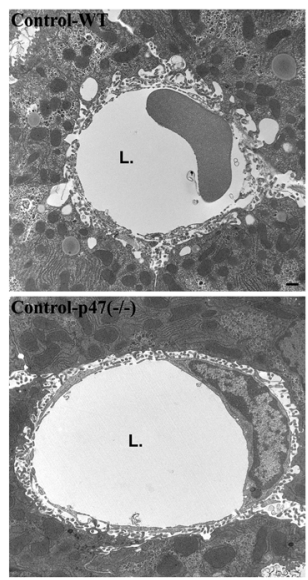
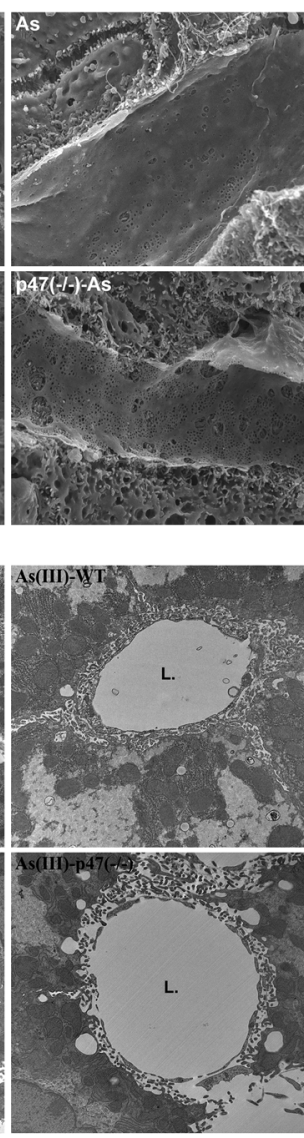

B

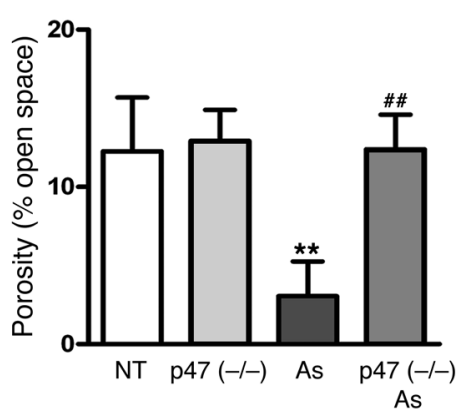

D

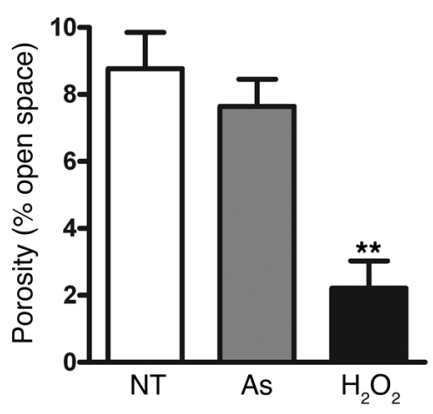

\section{Figure 4}

NADPH oxidase is required for arsenic-stimulated capillarization in vivo. (A) Matched wildtype and $\mathrm{p} 47^{\text {phox }}$ knockout C57BL/6 mice were untreated or exposed to $100 \mathrm{ppb}$ arsenite in their drinking water for 2 wk. Liver sections were imaged by scanning $E M$ at $\times 7,500$ magnification. (B) Porosity of liver sections in $\mathbf{A}$ was quantified as in Figure 1. Data are mean $\pm S D$; significance of differences was determined by ANOVA followed by Newman-Keuls post test ( $n=3$ mice per treatment). (C) Representative transmission EM images of liver sinusoids captured from ultrathin sections of mice in $\mathbf{A}$. $\mathrm{L}$, sinusoidal lumen. (D) SECs isolated from p47 $7^{\text {phox }}$ knockout mice were exposed ex vivo to either $2.5 \mathrm{mM}$ arsenic or $50 \mathrm{mM} \mathrm{H}_{2} \mathrm{O}_{2}$ for $8 \mathrm{~h}$. The cells were then fixed and imaged by scanning EM, and porosity was quantified as in Figure 1. Data $(m e a n \pm S D)$ indicate percent porosity of 5 separate cultures per group. ${ }^{* *} P<0.01$ versus control; \#\# $P<0.01$ versus arsenite. Scale bars: $1 \mu \mathrm{m}(\mathbf{A}) ; 0.1 \mu \mathrm{m}(\mathbf{C})$. have demonstrated that there was no increase in inflammatory cells in the livers of mice exposed for $2 \mathrm{wk}$ to the higher arsenic dose of $250 \mathrm{ppb}$ (23). Since arsenic-induced defenestration is fully manifested within $2 \mathrm{wk}$, these data suggest that arsenic directly affects the SECs or surrounding cells to induce capillarization rather than a through a mechanism requiring leukocyte oxidase activity. In the current study, we used 2 independent strategies to test whether activating SEC Nox2 oxidase was necessary and sufficient to effect phenotype change. First, p47phox is a canonical, essential cytosolic subunit of Nox2-based oxidase, and our results demonstrated that genetic deletion of this subunit prevented arsenic-stimulated sinusoidal generation of nitrotyrosine (Figure 5), loss of porosity (Figure $4 \mathrm{~A}$ ), and morphological changes in the space of Disse (Figure 4C). Nitrotyrosine staining colocalized with PECAM-1-positive SECs. Because superoxide is not capable of crossing cell membranes, our observation suggested that the SECs were the source of superoxide or other reactive intermediates required to react with $\mathrm{NO}$ to form peroxynitrite. Second, isolated SECs from wild-type or $\mathrm{p} 47$ phox knockout mice were used to confirm that Nox2-based oxidase generated superoxide in response to arsenic exposure and that this superoxide or its derivatives was sufficient to cause the morphological changes indicative of capillarization. Arsenic failed to decrease porosity of cells that were genetically deficient in Nox2-based oxidase activity, and decreasing arsenic-induced superoxide levels in wild-type cells effectively prevented loss of scavenging activity, defenestration, and junctional PECAM-1 expression. We used gp91ds-tat, an inhibitory peptide targeting Nox 2 interaction with $\mathrm{p} 47^{\mathrm{phox}}$, to implicate the
Nox2-based oxidase as being the central mediator of the oxidant response to arsenic. In contrast to the effects of the scrambled-tat peptide, in which the active targeting sequence in gp91ds-tat is rearranged (28), gp91ds-tat was completely effective in protecting the SECs. Final proof of the central role of the SEC Nox2-based oxidase in arsenic signaling was provided by the observation that preventing Rac1-GTPase activity provided protection from arsenic-stimulated defenestration. Rac1-GTPase is another essential component of the Nox2-based oxidase that provides an axis for enzyme stimulation in response to a number of endogenous ligands and environmental stimulants $(24,25)$. Thus, the data are consistent with SEC Nox2based oxidase directly contributing to endothelial dysfunction and suggest that this oxidase is the dominant isozyme for arsenic-stimulated superoxide generation and capillarization.

The data provide little support for a role of the other prevalent endothelial-expressed isozyme, Nox4-based oxidase, in the response to arsenic, because this isoform does not require 447 phox and thus should not be affected by either the $\mathrm{p} 47 \mathrm{phox}$ knockout or gp91ds-tat $(28,34)$. There is a single in vitro report indicating that overexpression of constitutively active type 1 VEGF receptor in an immortalized SEC line resulted in a 6-fold induction of Nox1, which increased apoptosis (35). However, the cell line was not well characterized as retaining SEC phenotype, and Nox1 is generally expressed at low levels in endothelial cells $(25,28,34)$. The in vivo data in the current study do not rule out contributions of the Nox2 oxidase in other liver cells, because stellate and Kupffer cells, as well as hepatocytes, express the Nox 2 anchor $(36,37)$. Nonetheless, the ex vivo data confirm the 

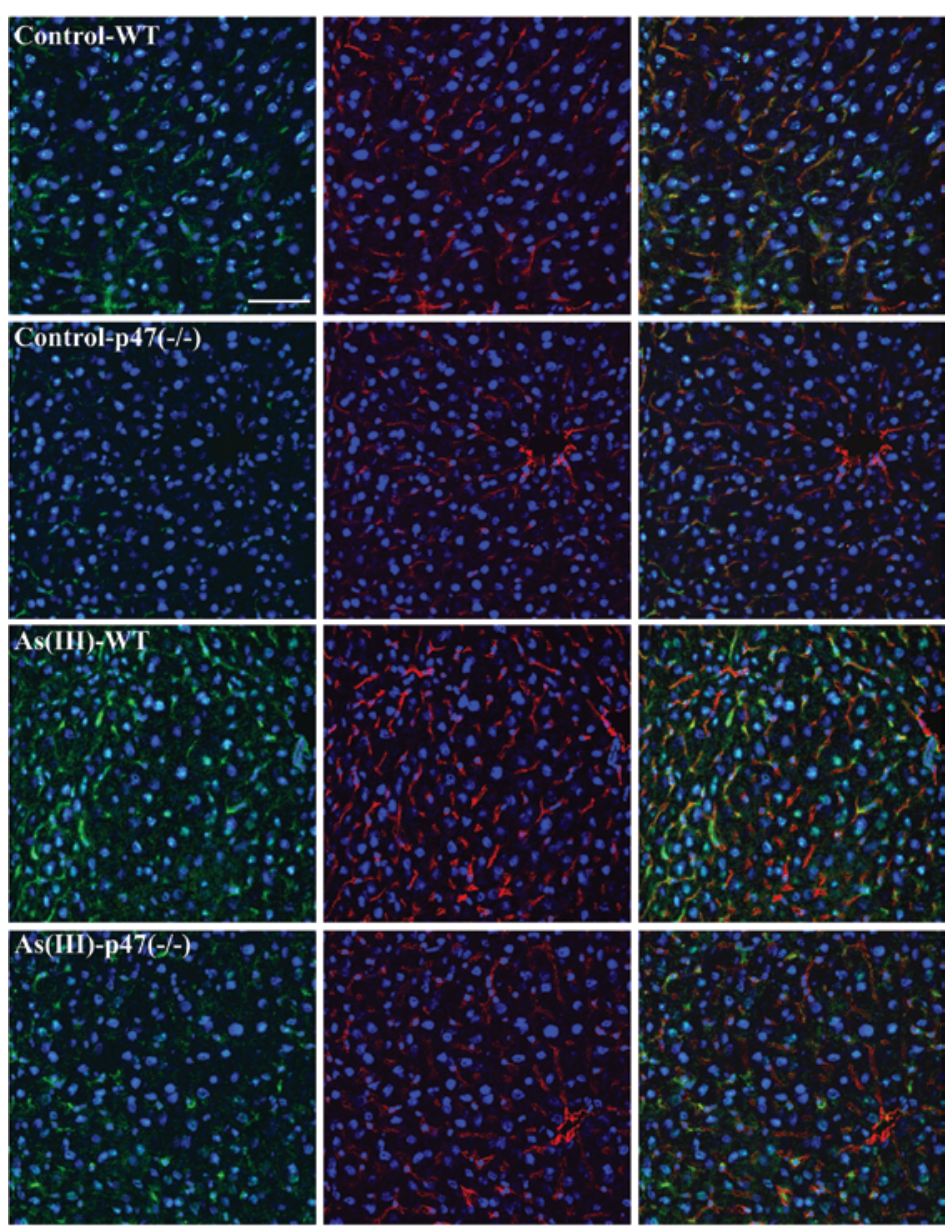

Nitrotyrosine

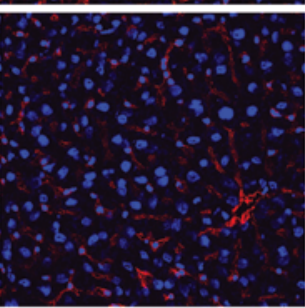

PECAM

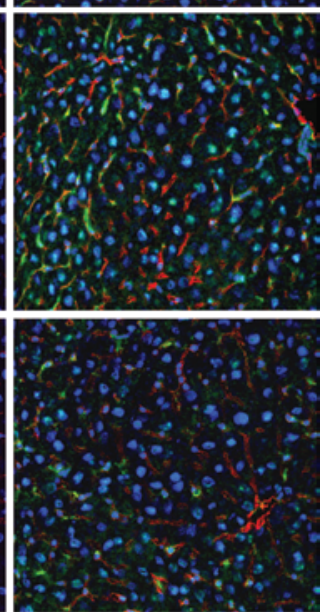

Merged

\section{Figure 5}

NADPH oxidase is required for arsenic-stimulated nitrotyrosine formation in vivo. Frozen liver sections of the mice from Figure 4 were fixed in $2 \%$ paraformaldehyde and immunostained for nitrotyrosine (green) and PECAM-1 (red). Nuclei were stained with DRAQ5 (blue). Sections were imaged at $\times 400$ and merged to indicate the degree of colocalization of nitrosylated proteins with sinusoids. Images are representative of sections of livers from 3 mice per group. Scale bar: $10 \mu \mathrm{m}$. necessary and sufficient role for SEC Nox2-based oxidase in both capillarization and functional loss, and additional oxidants from other liver cells would only add to this pathologic change in vivo.

Arsenic-stimulated superoxide generation may promote defenestration and capillarization by ROS-mediated signaling or quenching $\mathrm{NO}$ that is required for maintaining the fenestrated SEC phenotype. The data in Figure 4D suggest that $\mathrm{H}_{2} \mathrm{O}_{2}$ is effective in promoting SEC defenestration and thus may be the second messenger for these arsenic actions in the SECs. However, fenestrated endothelium is found in tissues constitutively expressing high levels of VEGF and VEGF-stimulated NO (38). DeLeve et al. demonstrated that the SEC phenotype was maintained by paracrine stimulation through hepatocyte- and stellate cell-derived VEGF-stimulated NO production in either the stellate cells or the SECs (15). In reciprocal regulation, the SEC NO suppresses stellate cell activation and collagen expression that facilitates fibrosis (16). Loss of NO contributes to pathogenic angiogenesis, fibrosis, and portal hypertension in the liver (39). Peroxynitrite formed from the reaction of superoxide and $\mathrm{NO}$ has been proposed as a pathogenic mediator of liver perfusion defects caused by obesity and insulin resistance (21). Nitrosylation of protein tyrosine residues is a marker of peroxynitrite formation, and the observation that arsenite failed to increase protein nitrosylation in $\mathrm{p} 47^{\mathrm{phox}}$ knockout mice (Figure 5) suggests that stimulation of superoxide generation and peroxynitrite formation is a primary mechanism for arsenic-induced remodeling of the liver vasculature and impaired function in the sinusoids. The data do not discriminate, however, between the significance of superoxide depletion of regulatory NO or peroxynitrite-mediated signaling to arsenic-stimulated SEC capillarization. Nonetheless, the fact that $\mathrm{H}_{2} \mathrm{O}_{2}$ is sufficient to reduce porosity suggests that both loss of $\mathrm{NO}$ and peroxynitrite formation are secondary mechanisms in arsenic-stimulated capillarization.

While the functional consequences of arsenic-stimulated, oxidantdependent signaling in SECs are unique to this cell type, the initiation of this signaling may be common to endothelial cells in most vascular beds. We observed that environmental exposure to arsenic stimulates angiogenesis in Matrigel plugs and tumor xenographs in vivo $(4,40)$ as well as tube formation by human microvascular cells in cultured Matrigel (41). While the isoforms were not specifically identified, arsenic was found to stimulate large-vessel endothelial and smooth muscle cell NADPH oxidases $(26,27)$ and quench bradykinin-stimulated NO generation in aortic endothelial cells (42) or NOdependent vasodilation in aortic rings (43). In addition, endothelial peroxynitrite formation appears to contribute to arsenic-promoted atherosclerosis in genetic mouse models (44). Thus, it is likely that the arsenic exposures in the current studies had systemic effects in most vascular beds. However, other pathological endpoints, such as atherosclerotic plaque formation, vessel wall thickening, or peripheral vascular disease, would not be expected to occur in a mouse within the 2 -wk exposure period examined in the current studies. Nonetheless, the importance of the SEC- and liver-specific observations is that 
A
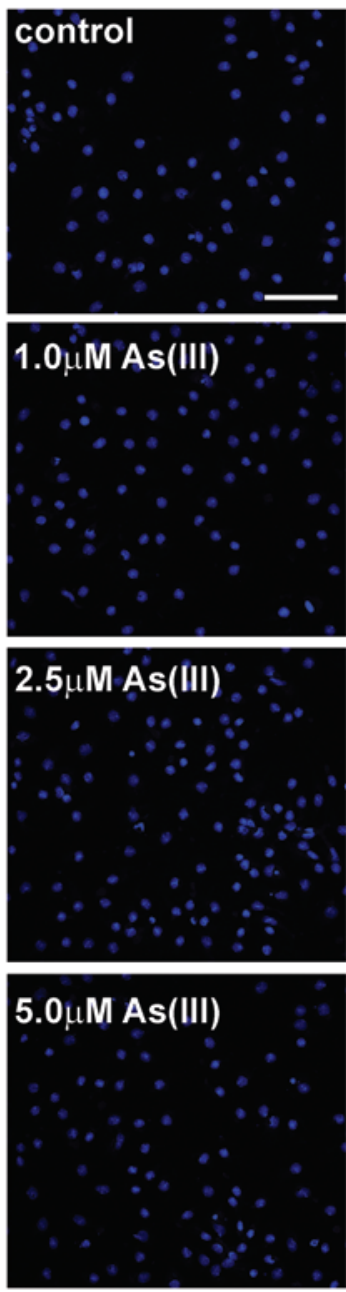

Nuclei
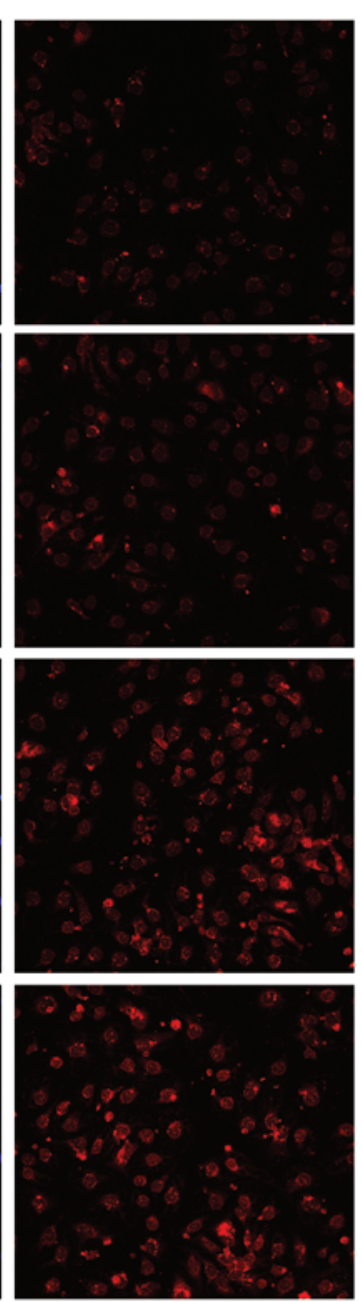

HE
B

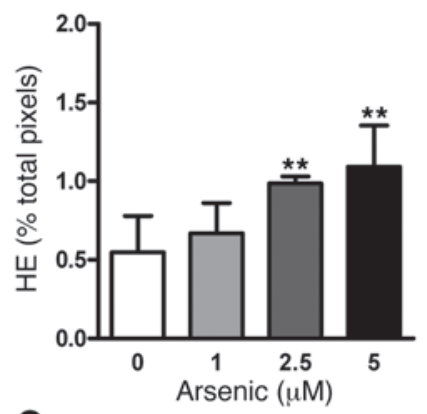

C

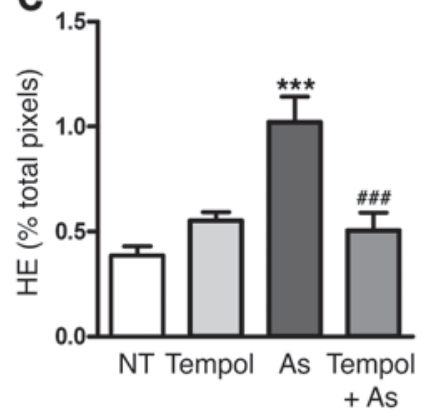

\section{D}

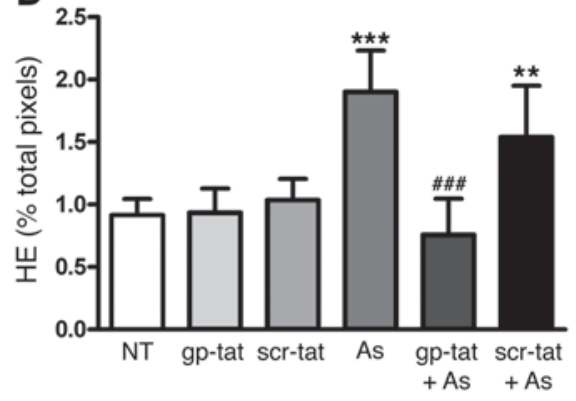

\section{Figure 6}

Arsenic-stimulated superoxide generation is inhibited by tempol and gp91ds-tat peptide. (A) Primary SECs isolated from mice were pre-loaded with $5 \mu \mathrm{M}$ dihydroethidium for $10 \mathrm{~min}$ prior to a 30-min arsenite exposure. Cells were fixed and imaged for hydroethidium (HE; red) fluorescence and DAPI (blue) stained nuclei. Scale bar: $10 \mu \mathrm{m}$. (B) Percent (mean \pm SD) positive hydroethidium staining, normalized to the percentage of positive nuclei staining ( $n=4$ cultures from 2 livers). (C) SECs were preloaded with $5 \mu \mathrm{M}$ dihydroethidium with and without $1 \mathrm{mM}$ tempol $10 \mathrm{~min}$ prior to a $30-\mathrm{min}, 2.5-$ $\mu \mathrm{M}$ arsenite exposure and then imaged and analyzed as in $\mathbf{B}$ ( $n=4$ cultures). (D) Cells were preincubated with dihydroethidium in the presence or absence of $10 \mu \mathrm{M}$ gp91ds-tat (gp-tat) or scrambled-tat (scrtat) peptide for $30 \mathrm{~min}$ prior to a 2.5- $\mu \mathrm{M}$ arsenite exposure ( $n=6$ cultures from 3 livers). In $\mathbf{C}$ and $\mathbf{D}$, significance of differences was determined by ANOVA followed by NewmanKeuls post test. ${ }^{* *} P<0.01$, ${ }^{\star * \star} P<0.001$ versus control; $\# \# P<0.001$ versus arsenite. capillarization is a significant and relatively early pathogenic event. Sustained capillarization and loss of SEC scavenging may precede arsenic-promoted systemic disease or enhance deleterious systemic effects of arsenic by impairing clearance of acetylated lipids or modified proteins that are known risk factors for vascular and metabolic disease. Further studies are needed to determine whether the arsenicinduced sinusoidal morphological changes and loss of SEC scavenger function are initial steps in arsenic-induced vascular disease or are limited to pathogenic changes in the liver.

The finding of morphological and functional changes in livers of mice exposed to concentrations of arsenic that promote human diseases other than cancer is notable, because mice are often several orders of magnitude less sensitive than humans to the carcinogenic and lethal effects of arsenic. However, cardiovascular effects may be more sensitive disease endpoints in humans drinking the same levels of arsenic used in the current studies $(1,2,7)$, and our present findings suggest that the mouse is an appropriate model for studying the etiology of arsenic-promoted disease. In addition, these studies provide valuable information regarding gene environment interactions. Hsueh et al. suggested that genetic polymorphisms in the NADPH oxidase p22 subunit may contribute to arsenic-related hypertension in Taiwan (8).
In summary, the current data support an essential for an NADPH oxidase in a form of pathogenic vascular remodeling that can contribute to liver disease as well as to systemic hypertension and atherogenesis. The Nox2-based oxidase in SECs appears to be directly activated by environmental exposures to arsenic, and this activation is central to arsenic-induced capillarization and loss of SEC scavenging function. The apparent requirement for Rac1GTPase activity (Figure 8) suggests that Rac1 and oxidase activation are downstream of the target of arsenic in the endothelial cells and that peroxynitrite formation may be a pathogenic endpoint of arsenic signaling in SECs. However, future experiments are needed to identify the molecular targets on endothelial cells that initiates arsenic signaling for oxidase activation. Identifying this target may reveal important pathogenic mechanisms promoting SECs and possibly systemic endothelial dysfunction that contribute to the etiology of environmentally derived vascular diseases.

\section{Methods}

Animal exposure. Animal experiments were performed in agreement with institutional guidelines for animal safety and welfare at the University of Pittsburgh. Wild-type C57BL/6 Tac mouse exposures were performed as described previously $(22,23)$. Serial dilutions were used to prepare drinking water with sodium 


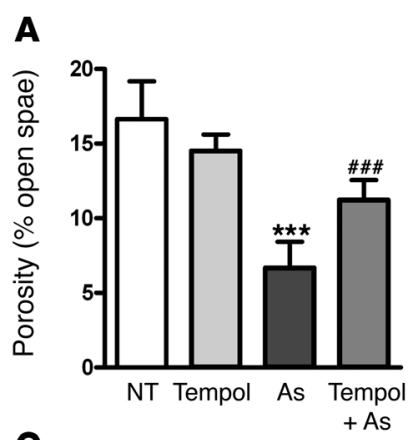

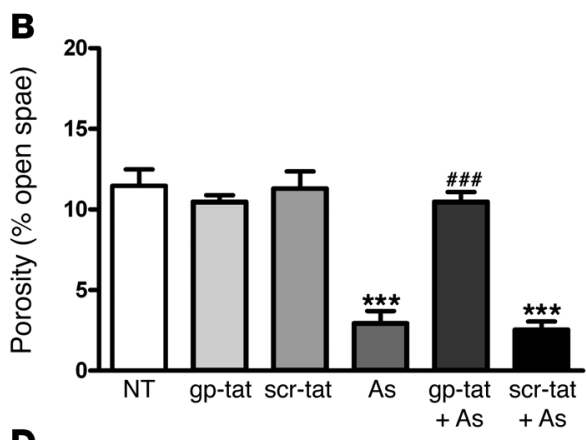

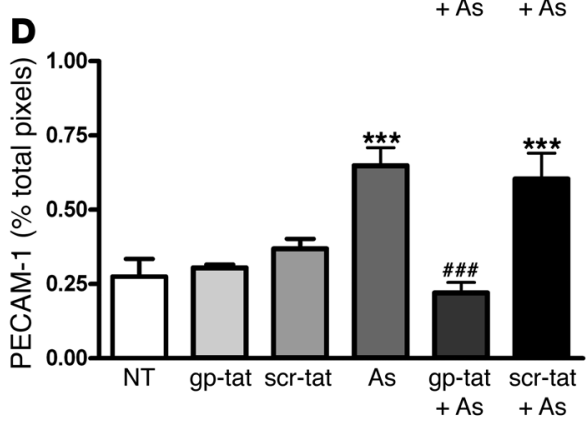

Figure 7

Arsenite-stimulated defenestration and junctional PECAM-1 expression is inhibited by tempol and gp91dstat peptide. Cultured SECs were preincubated with tempol (A and $\mathbf{C}$ ) or with gp91ds-tat or scrambled-tat peptide ( $\mathbf{B}$ and $\mathbf{D}$ ) and then exposed to $2.5 \mu \mathrm{M}$ for $8 \mathrm{~h}$. At the end of exposure, groups of cells were analyzed for porosity (A and B), as in Figure 1B, or PECAM-1 expression changes (C and D), as in Figure 2B. Significant differences between groups were determined by ANOVA followed by Newman-Keuls post test $(n=5$ cultures from 3 livers.). ${ }^{* \star \star} P<0.001$ versus control; $\# \# P<0.001$ versus arsenite.

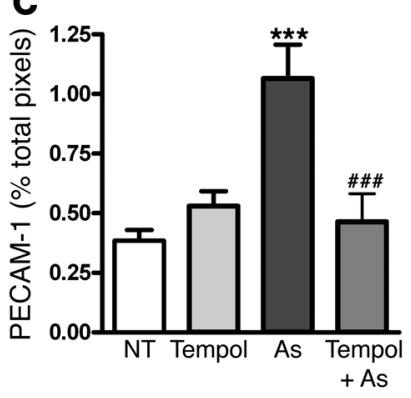

arsenite concentrations of 10, 50, 100, or $250 \mathrm{ppb}$. C57BL/6Ai p47phox knockout mice (Taconic Farms) were housed under pathogen-free conditions in autoclaved microisolator cages with Alpha-dri bedding (Shepherd Specialty Papers) to reduce footpad irritation and edema. The mice were treated with $380 \mathrm{mg}$ broad-spectrum sulfamethoxazole-trimethoprim antibiotic per $500 \mathrm{ml}$ drinking water according to the vendor's instructions (Taconic Farms). C57BL/ 6 mice housed in the same manner and treated with antibiotic served as controls for the C57BL/6Ai p47phox knockout mice. There were no observable infections during the arsenic exposures or at the time of necropsy. All water was changed 3 times per week to maintain effective concentrations of arsenite and antibiotic. Liver perfusions with collagenase, fixative, or modified lipids and proteins were performed following sodium pentobarbital anesthesia. All other mice were euthanized with $\mathrm{CO}_{2}$.

SEC isolation and ex vivo culture. Nonparenchymal cells from C57BL/6 mouse livers were obtained from the laboratory of T. Billiar (University of Pittsburgh, Pittsburgh, Pennsylvania, USA). The cells were isolated by standard collagenase digestion and liver cell separation, as described previously $(45,46)$. Briefly, livers were perfused with buffered collagenase to obtain a single-cell suspension. Parenchymal cells (hepatocytes) were removed using low-speed centrifugation at $50 \mathrm{~g}$. The remaining non-parenchymal cells (SECs, Kupffer cells, and Stellate cells) were placed onto a 2-step 25\% and 50\% Percoll gradient and centrifuged at $900 \mathrm{~g}$ for $20 \mathrm{~min}$. SECs and Kupffer cells at the $50 \%$ interface were removed, and Kupffer cells were eliminated by selective adherence to an untreated Petri dish. The nonadherent fraction yielded approximately $0.5 \times 10^{6} \mathrm{SECs}$ per liver with a purity of $95 \%$ fenestrated cells, as determined by scanning EM and low PECAM-1 surface expression. Approximately 5,000 SECs were then plated onto $0.1 \%$ gelatin-coated coverslips and incubated overnight in Molecular, Cellular, and Developmental Biology-131 (MCDB-131) medium containing $0.5 \%$ fetal bovine serum, $20 \mathrm{ng} / \mathrm{ml}$ murine VEGF, $50 \mu \mathrm{M}$ ascorbic acid, $10 \mathrm{ng} / \mathrm{ml}$ EGF, $25 \mu \mathrm{g} / \mathrm{ml}$ gentamicin, and $1 \mu \mathrm{g} / \mathrm{ml}$ hydrocortisone. The following day, SEC medium was replaced with medium containing half the amount of VEGF. Sodium arsenite (1-5 $\mu \mathrm{M})$ was added to the SECs for $8 \mathrm{~h}$, and the cells were fixed and prepared for scanning EM or immunofluorescence. All experiments were repeated 3 times (cells from 3 separate livers) with duplicate cultures from each mouse, for a total of 6 cultures.
Microscopy and quantitative imaging. At necropsy, livers were either excised and snap frozen in liquid nitrogen or perfusion fixed with glutaraldehyde in preparation for immunofluorescent analysis of proteins or scanning EM of tissue ultrastructure. Tissues for immunofluorescence and scanning EM were prepared and imaged as previously described $(22,23,47)$. For quantitative immunofluorescence, 3 representative $\times 400$ images from individual coverslips were captured by a microscopist blinded to treatments, as described previously $(22,23)$. The percentage of positive pixels in the 3 images was averaged to give a single value per coverslip. Values were normalized by dividing the percent thresholded area of PECAM expression by percent thresholded area of nuclei. Porosity, the percent of open space in sinusoidal vessels or cultured cells, was measured in representative $\times 7,500$ or $\times 10,000$ scanning EM images of vessels and cells, respectively, as described previously $(22,23$, 48). Briefly, images from $3-\mu \mathrm{m}$-thick liver sections were captured with a JSM6330F scanning electron microscope, and images of 10 midlobular sinusoids per mouse were measured for porosity using MetaMorph software (version 7.0; Molecular Devices). Within a defined midlobular region of in representative sinusoids, total sinusoidal area and the open area of individual fenestrae (20-500 $\mathrm{nm}$ diameter) and gaps (>500 $\mathrm{nm}$ diameter) were quantified in square microns. These open areas were summed, divided by the total areas of the vessels examined, and multiplied by 100 to give the porosity as percent of open area. The porosities of the 10 separate vessels were averaged to give a single value per mouse. Ultrathin 70-nm sections were imaged on a JEM 1210 transmission electron microscope (JEOL) at $80 \mathrm{kV}$ to evaluate changes in SEC basement membranes and integrity of the space of Disse, as described previously $(22,23,48)$. There was little inter- and intraoperator variation in quantifying porosity or immunofluorescence, as evidenced by the close agreement between the values obtained in the current studies and our 2 previous studies of the effects of arsenic on the SEC $(22,23)$.

Superoxide detection. Primary SECs were isolated and cultured as described above. Dihydroethidium $(5 \mu \mathrm{M})$ was loaded into cells for $10 \mathrm{~min}$ before adding arsenite for $30 \mathrm{~min}$. The cells were then fixed and stained with DRAQ5. Quantitative immunofluorescence was used to determine changes in dihydroethidium oxidation normalized to percentage of nuclear pixels, as described above. To scavenge superoxide, $1 \mathrm{mM}$ tempol (Sigma-Aldrich) was added for $10 \mathrm{~min}$ prior to adding arsenite. To inhibit 
A

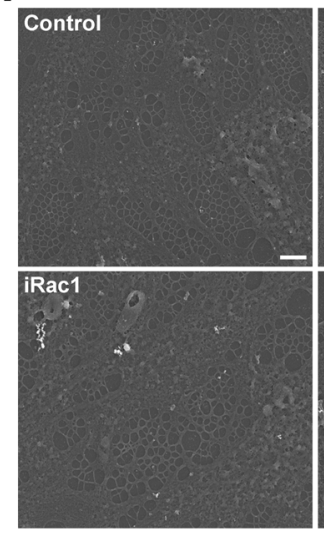

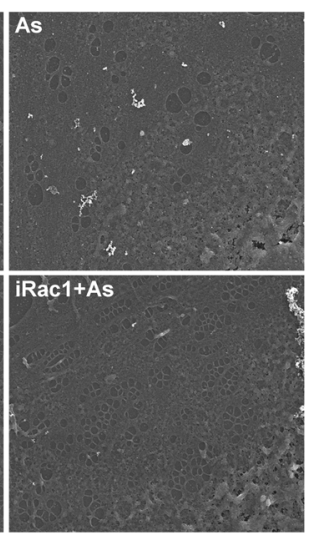

B

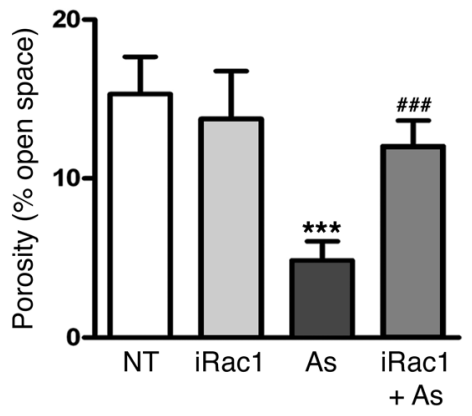

C

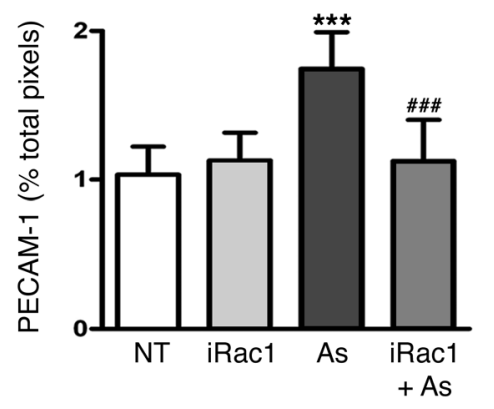

Figure 8

Rac1 inhibition prevents arsenite-stimulated defenestration and PECAM-1 expression. Cultured SECs were incubated overnight with or without $50 \mu \mathrm{M}$ of Rac1-GTPase activity inhibitor NSC23766 (iRac1). The cells were then left untreated or exposed to $2.5 \mu \mathrm{M}$ arsenite for $8 \mathrm{~h}$. Cells were then fixed for scanning EM imaging of porosity (A and B), as in Figure 1B, or immunofluorescence imaging of PECAM-1 and DRAQ5 expression (C), as in Figure 2B. Significant differences between groups were determined by ANOVA followed by Newman-Keuls post test $(n=5$ cultures from 3 livers). ${ }^{* *} P<0.001$ versus control; ${ }^{\# \# \#} P<0.001$ versus arsenite. Scale bar: $1 \mu \mathrm{m}$.

Nox2-based oxidase, $10 \mu \mathrm{M}$ of either gp91ds-tat or scrambled-tat peptide synthesized as described previously (28) and dissolved in $0.01 \mathrm{~N}$ acetic acid in saline - were added to cells $30 \mathrm{~min}$ prior to adding arsenic. All experimental groups contained at least 6 SEC cultures with duplicate coverslips of cells from 3 separate livers.

Modified albumin synthesis. FITC- or biotin- labeled native or succinylated BSA was prepared as follows. Briefly, a 10-M excess of FITC (SigmaAldrich) or biotin-NHS (Pierce), freshly prepared in DMSO, was added into $1 \mathrm{ml}$ of BSA solution $\left(100 \mathrm{mg} / \mathrm{ml}\right.$ in $\left.1 \mathrm{M} \mathrm{NaHCO}_{3}\right)$. The reaction was allowed to proceed at $4{ }^{\circ} \mathrm{C}$ for $1 \mathrm{~h}$. The reaction mixture was then either thoroughly dialyzed against PBS, to obtain labeled native BSA, or reacted with 425 -mg aliquots of succinyl anhydride at 15 -min intervals. The succinylation continued overnight at $4^{\circ} \mathrm{C}$, and then the reaction mixtures were purified by dialysis. The degree of succinylation of free amino groups was estimated to be $90 \%$ by reacting the remaining $\mathrm{NH}_{2}$ groups with $2,4,6$ trinitrobenzene sulfonic acid (Pierce).

Modified albumin uptake. To demonstrate SEC-specific uptake, $150 \mathrm{mg} /$ $\mathrm{kg}$ of FITC-labeled BSA or succinylated BSA was injected into the mouse tail vein in $200 \mu \mathrm{l}$ saline. After $10 \mathrm{~min}$, livers were excised, fixed in $4 \%$ paraformaldehyde, and sectioned for confocal microscopic analysis. Quantitative uptake of succinylated BSA was measured in control and arsenicexposed mice by infusing a mixture of FITC-labeled acetylated LDL (BTI Technologies) and biotin-labeled succinylated BSA $(150 \mathrm{mg} / \mathrm{ml}$ saline $)$ into the vena cava over $3 \mathrm{~min}$. Livers were then excised, snap frozen in liquid $\mathrm{N}_{2}$, and sectioned. To control for differential perfusion of liver lobes, microscopists blinded to treatment selected liver sections with equivalent levels of FITC-labeled acetylated LDL fluorescence. Total protein was extracted from these sections, and equal amounts were assayed for biotinylated albumin by immunoblotting. Likewise, cultured control SECs or SECs exposed to arsenic for $24 \mathrm{~h}$ were incubated with $20 \mu \mathrm{g} / \mathrm{ml}$ biotin-labeled succinylated BSA for $10 \mathrm{~min}$, rinsed 3 times with PBS, and then extracted for total protein to determine modified albumin uptake. Biotin in the $75-\mathrm{kDa}$ BSA protein band was detected on transfer membranes using HRP-conjugated anti-biotin antibody (Cell Signaling) and enhanced chemiluminescence. Densities of detected protein bands were quantified using NIH ImageJ software (version 1.28x; http://rsbweb.nih.gov/ij/) and normalized to band densities of immunodetected $\beta$-actin in the same sample.
Materials. NSC23766 (EMD) was added to cells overnight to inhibit Rac1 GTPase activity prior to arsenite exposure. Primary antibodies used for immunodetection were rat monoclonal anti-mouse CD31 (BD); monoclonal anti- $\beta$-actin (Sigma-Aldrich); and polyclonal antinitrotyrosine (Invitrogen). Secondary antibodies included Alexa Fluor 488-conjugated goat anti-rat (Invitrogen), Alexa Fluor 594-conjugated goat anti-rat (Invitrogen), Alexa Fluor 488-conjugated goat anti-rabbit (Invitrogen), and HRP-conjugated sheep anti-mouse (GE Healthcare). DRAQ5 was used to stain nuclei.

Statistics. Mice and SECs exposed to various dose of arsenic were analyzed using 1-way ANOVA followed by Dunnet's or Newman-Keuls post test for difference between treatments. All statistical analyses were performed using GraphPad statistical software version 4.0. A $P$ value less than 0.05 was considered significant.

\section{Acknowledgments}

The authors thank Simon Watkins for use of the confocal and electron microscopes and for processing of tissues and cells at the Center for Biological Imaging. We also thank Timothy Billiar for the donation of SECs and his technical assistants, Carol Meiers and Danielle Reiser, for their outstanding technical assistance in SEC isolations. This work was supported by NIEHS grant ES013781 (to A. Barchowsky), NCI grant CA76541 (to D.B. Stolz), NHLBI grants HL68688 (to S. Li) and HL079207 (to P.J. Pagano), EPA STAR Fellowship FP-91654201 (to A.C. Straub), and an internal grant from the Office of the Senior Vice Chancellor for the Health Sciences, University of Pittsburgh. P.J. Pagano is an Established Investigator of the American Heart Association (AHA 0540029N).

Received for publication January 22, 2008, and accepted in revised form October 8, 2008.

Address correspondence to: Aaron Barchowsky, Department of Occupational and Environmental Health, Graduate School of Public Health, University of Pittsburgh, Bridgeside Point, 100 Technology Drive, Pittsburgh, Pennsylvania 15219, USA. Phone: (412) 624-8864; Fax: (412) 624-9361; E-mail: aab20@pitt.edu. 
1. Zierold, K.M., Knobeloch, L., and Anderson, H. 2004. Prevalence of chronic diseases in adults exposed to arsenic-contaminated drinking water. Am. J. Public Health. 94:1936-1937.

2. Navas-Acien, A., et al. 2005. Arsenic exposure and cardiovascular disease: a systematic review of the epidemiologic evidence. Am. J. Epidemiol. 162:1037-1049.

3. Meliker, J.R., Wahl, R.L., Cameron, L.L., and Nriagu, J.O. 2007. Arsenic in drinking water and cerebrovascular disease, diabetes mellitus, and kidney disease in Michigan: a standardized mortality ratio analysis. Environ. Health. 6:4

4. Soucy, N.V., et al. 2005. Neovascularization and angiogenic gene expression following chronic arsenic exposure in mice. Cardiovasc. Toxicol. 5:29-42.

5. Kamat, C.D., et al. 2005. Role of HIF signaling on tumorigenesis in response to chronic low-dose arsenic administration. Toxicol. Sci. 86:248-257.

6. Yuan, Y., et al. 2007. Acute myocardial infarction mortality in comparison with lung and bladder cancer mortality in arsenic-exposed region II of Chile from 1950 to 2000. Am. J. Epidemiol. 166:1381-1391.

7. Chen, Y., et al. 2007. Arsenic exposure from drinking water, dietary intakes of B vitamins and folate, and risk of high blood pressure in Bangladesh: a population-based, cross-sectional study. Am. J. Epidemiol. 165:541-552.

8. Hsueh, Y.M., et al. 2005. Genetic polymorphisms of oxidative and antioxidant enzymes and arsenicrelated hypertension. J. Toxicol. Environ. Health A. 68:1471-1484

9. Mazumder, D.N. 2005. Effect of chronic intake of arsenic-contaminated water on liver. Toxicol. Appl. Pharmacol. 206:169-175.

10. Falkowska-Hansen, B., Falkowski, M., Metharom, P., Krunic, D., and Goerdt, S. 2007. Clathrincoated vesicles form a unique net-like structure in liver sinusoidal endothelial cells by assembling along undisrupted microtubules. Exp. Cell Res. 313:1745-1757.

11. Elvevold, K., Smedsrod, B., and Martinez, I. 2008. The liver sinusoidal endothelial cell: a cell type of controversial and confusing identity. Am. J. Physiol. Gastrointest. Liver Physiol. 294:G391-G400.

12. Warren, A., et al. 2006. T lymphocytes interact with hepatocytes through fenestrations in murine liver sinusoidal endothelial cells. Hepatology. 44:1182-1190

13. Hilmer, S.N., et al. 2005. Age-related changes in the hepatic sinusoidal endothelium impede lipoprotein transfer in the rat. Hepatology. 42:1349-1354

14. DeLeve, L.D. 2007. Hepatic microvasculature in liver injury. Semin. Liver Dis. 27:390-400.

15. DeLeve, L.D., Wang, X., Hu, L., McCuskey, M.K., and McCuskey, R.S. 2004. Rat liver sinusoidal endothelial cell phenotype is maintained by paracrine and autocrine regulation. Am. J. Physiol. Gastrointest.Liver Physiol. 287:G757-G763.

16. DeLeve, L.D., Wang, X., and Guo, Y. 2008. Sinusoidal endothelial cells prevent rat stellate cell activation and promote reversion to quiescence. Hepatology. 48:920-930.

17. Hasegawa, T., et al. 2002. Mechanism of superoxide anion production by hepatic sinusoidal endothelial cells and Kupffer cells during short-term ethanol perfusion in the rat. Liver. 22:321-329.

18. Cogger, V.C., et al. 2004. The effects of oxidative stress on the liver sieve. J. Hepatol. 41:370-376.

19. Cogger, V.C., et al. 2006. Hyperlipidemia and surfactants: The liver sieve is a link. Atherosclerosis. 189:273-281.

20. McLean, A.J., et al. 2003. Age-related pseudocapillarization of the human liver. J. Pathol. 200:112-117.

21. Brock, R.W., and Dorman, R.B. 2007. Obesity, insulin resistance and hepatic perfusion. Microcirculation. 14:339-347.

22. Straub, A.C., et al. 2007. Arsenic stimulates sinusoidal endothelial cell capillarization and vessel remodeling in mouse liver. Hepatology. 45:205-212.

23. Straub, A.C., et al. 2007. Low level arsenic promotes progressive inflammatory angiogenesis and liver blood vessel remodeling in mice. Toxicol. Appl. Pharmacol. 222:327-336.

24. Ushio-Fukai, M., and Alexander, R.W. 2004. Reactive oxygen species as mediators of angiogenesis signaling: role of $\mathrm{NAD}(\mathrm{P}) \mathrm{H}$ oxidase. Mol. Cell. Biochem. 264:85-97.

25. Lyle, A.N., and Griendling, K.K. 2006. Modulation of vascular smooth muscle signaling by reactive oxygen species. Physiology (Bethesda). 21:269-280.

26. Smith, K.R., Klei, L.R., and Barchowsky, A. 2001. Arsenite stimulates plasma membrane NADPH oxidase in vascular endothelial cells. Am. J. Physiol. Lung Cell Mol. Physiol. 280:L442-L449.

27. Lynn, S., Gurr, J.R., Lai, H.T., and Jan, K.Y. 2000. $\mathrm{NADH}$ oxidase activation is involved in arseniteinduced oxidative DNA damage in human vascular smooth muscle cells. Circ. Res. 86:514-519.

28. Rey, F.E., Cifuentes, M.E., Kiarash, A., Quinn, M.T., and Pagano, P.J. 2001. Novel competitive inhibitor of $\mathrm{NAD}(\mathrm{P}) \mathrm{H}$ oxidase assembly attenuates vascular $\mathrm{O}(2)(-)$ and systolic blood pressure in mice. Circ. Res. 89:408-414.

29. Gao, Y., Dickerson, J.B., Guo, F., Zheng, J., and Zheng, Y. 2004. Rational design and characterization of a Rac GTPase-specific small molecule inhibitor. Proc. Natl. Acad. Sci. U. S. A. 101:7618-7623.

30. Xu, B., et al. 2003. Capillarization of hepatic sinusoid by liver endothelial cell-reactive autoantibodies in patients with cirrhosis and chronic hepatitis. Am. J. Pathol. 163:1275-1289.

31. Tsuneyama, K., et al. 2003. A comparative histological and morphometric study of vascular changes in idiopathic portal hypertension and alcoholic fibrosis/ cirrhosis. Histopathology. 43:55-61.

32. Flora, S.J., Pant, S.C., Malhotra, P.R., and Kannan, G.M. 1997. Biochemical and histopathological changes in arsenic-intoxicated rats coexposed to ethanol. Alcohol. 14:563-568.

33. Dorman, R.B., et al. 2006. NAD(P)H oxidase contributes to the progression of remote hepatic paren- chymal injury and endothelial dysfunction, but not microvascular perfusion deficits. Am. J. Physiol. Gastrointest. Liver Physiol. 290:G1025-G1032.

34. Quinn, M.T., Ammons, M.C., and DeLeo, F.R. 2006. The expanding role of NADPH oxidases in health and disease: no longer just agents of death and destruction. Clin. Sci. (Lond.). 111:1-20.

35. Kobayashi, S., Nojima, Y., Shibuya, M., and Maru, Y. 2004. Nox1 regulates apoptosis and potentially stimulates branching morphogenesis in sinusoidal endothelial cells. Exp.Cell Res. 300:455-462.

36. Reinehr, R., Becker, S., Eberle, A., Grether-Beck, S., and Haussinger, D. 2005. Involvement of NADPH oxidase isoforms and Src family kinases in CD95dependent hepatocyte apoptosis. J. Biol. Chem. 280:27179-27194.

37. Teufelhofer, O., et al. 2005. Superoxide generation from Kupffer cells contributes to hepatocarcinogenesis: studies on NADPH oxidase knockout mice. Carcinogenesis. 26:319-329.

38. Maharaj, A.S., Saint-Geniez, M., Maldonado, A.E., and D'Amore, P.A. 2006. Vascular endothelial growth factor localization in the adult. Am.J. Pathol. 168:639-648.

39. Langer, D.A., and Shah, V.H. 2006. Nitric oxide and portal hypertension: interface of vasoreactivity and angiogenesis. J. Hepatol. 44:209-216.

40. Soucy, N.V., et al. 2003. Arsenic stimulates angiogenesis and tumorigenesis in vivo. Toxicol. Sci. 76:271-279.

41. Klei, L.R., and Barchowsky, A. 2008. Positive signaling interactions between arsenic and ethanol for angiogenic gene induction in human microvascular endothelial cells. Toxicol. Sci. 102:319-327.

42. Barchowsky, A., Klei, L.R., Dudek, E.J., Swartz, H.M., and James, P.E. 1999. Stimulation of reactive oxygen, but not reactive nitrogen species, in vascular endothelial cells exposed to low levels of arsenite. Free Radic. Biol. Med. 27:1405-1412.

43. Pi, J., et al. 2003. A potential mechanism for the impairment of nitric oxide formation caused by prolonged oral exposure to arsenate in rabbits. Free Radic. Biol. Med. 35:102-113.

44. Bunderson, M., et al. 2004. Arsenic exposure exacerbates atherosclerotic plaque formation and increases nitrotyrosine and leukotriene biosynthesis. Toxicol. Appl. Pharmacol. 201:32-39.

45. Seglen, P.O. 1976. Preparation of isolated rat liver cells. Methods Cell Biol. 13:29-83.

46. Ross, M.A., Sander, C.M., Kleeb, T.B., Watkins, S.C., and Stolz, D.B. 2001. Spatiotemporal expression of angiogenesis growth factor receptors during the revascularization of regenerating rat liver. Hepatology. 34:1135-1148

47. Wack, K.E., et al. 2001. Sinusoidal ultrastructure evaluated during the revascularization of regenerating rat liver. Hepatology. 33:363-378.

48. Stolz, D.B., et al. 1999. Cationic colloidal silica membrane perturbation as a means of examining changes at the sinusoidal surface during liver regeneration. Am. J. Pathol. 155:1487-1498. 